\title{
EXISTENCE THEOREMS FOR SOME SYSTEMS OF QUASI-VARIATIONAL INEQUALITIES PROBLEMS ON UNIFORMLY PROX-REGULAR SETS
}

\author{
NARIN PETRot AND JitTIPORn SUWANNAWIT
}

\begin{abstract}
In this paper, some systems of quasi-variational inequality problems are considered on a class of nonconvex sets, as uniformly prox-regular sets. Some sufficient conditions for the existence solution of the considered problems are provided. Also, some interesting remarks are discussed. The results which are presented in this paper are more general, and may be viewed as an extension, improvement and refinement of the previously known results in the litterateurs.
\end{abstract}

Mathematics subject classification (2010): 47H05, 49J40, 49J52.

Keywords and phrases: System of quasi-variational inequalities problems, uniformly prox-regular set, proximal normal cone, strongly monotone mapping, Lipschitzain continuous mapping, Hausdorff Lipschitz continuous.

\section{REFERENCES}

[1] A. Bensoussan, M. Goursat and J. L. Lions, Control impulsinnel et inequations quasivariationnelles stationaries, Comptes Rendus de l'Académie des Sciences, 276, (1973), 1279-1284.

[2] M. BounKHEL, L. T. TADJ AND A. HAMDI, Iterative schemes to solve nonconvex variational problems, Journal of Inequalities in Pure and Applied Mathematics, 4, (2003), 14 pages.

[3] S. S. Chang, Variational inequality and complementarity problem theory with applications, Shanghai Scientific and Tech. Literature Publishing House, Shanghai, (1991).

[4] F. H. Clarke, Optimization and Nonsmooth Analysis, Wiley-Interscience, New York, (1983).

[5] Y. J. CHO, J. K. KIM AND R. U. VERMA, A class of nonlinear variational inequalities involving partially relaxed monotone mappings and general auxiliary principle, Dynamic Systems and Applications, 11, (2002), 333-338.

[6] Z. F. H. Clarke, Yu. S. Ledyaev, R. J. Stern And P. R. Wolenski, Nonsmooth Analysis and Control Theory, Springer-Verlag, New York, (1998).

[7] S. S. Chang AND L. QING, Random variational inequalities and random saddle point theorems, Applied Mathematics and Mechanics, Special issue, (1993), 132-137.

[8] F. H. Clarke, R. J. STERn AND P. R. Wolens Ki, Proximal smoothness and the lower $C^{2}$ property, Journal of Convex Analysis, 2(1/2), (1995), 117-144.

[9] J. K. KIM AND K. S. KIM, On new systems of generalized nonlinear mixed quasivariational inequalities with two-variable operators, Taiwanese Journal of Mathematics, 11(3), (2007), 867-881.

[10] A. MoudAFI, An algorithmic approach to prox-regular variational inequalities, Applied Mathematics and Computation, 155, (2004), 845-852.

[11] A. MoudAFI, Projection methods for a system of nonconvex variational inequalities, Nonlinear Analysis: Theory, Methods \& Applications, 71(1-2), (2009), 517-520.

[12] J. S. B. NADLER, Multi-valued contraction mappings, Pacific Journal of Mathematics, 30, (1969), 475-488.

[13] M. A. Noor, Generalized set-valued mixed nonlinear quasi variational inequalities, The Korean Journal of Computational \& Applied Mathematics, 5(1), (1998), 73-89.

[14] M. A. NooR, Iterative schemes for nonconvex variational inequalites, Journal of Optimization Theory and Applications, 121, (2004), 385-395. 
[15] M. A. Noor, Variational inequalities and applications, Lecture Notes, Mathematics Department, COMSATS Institute of information Technology, Islamabad, Pakistan, (2007-2009).

[16] M. A. NOOR AND Z. HUANG, An iterative scheme for a system of quasi variational inequalities, Journal of Mathematical Inequalities, 1(1), (2007), 31-38.

[17] M. A. Noor, N. Petrot AND J. Sunannawit, Existence theorems for multivalued variational inequality problems on uniformly prox-regular sets, Optimization Letters, (2012), 13 pages, doi:10.1007/s11590-012-0545-x.

[18] N. Petrot, A resolvent operator technique for approximate solving of generalized system mixed variational inequality and fixed point problems, Applied Mathematics Letters, 23, (2010), 440-445.

[19] N. Petrot, Some existence theorems for nonconvex variational inequalities problems, Abstract and Applied Analysis, 2010, (2010), Article ID 472760, 9 pages, doi:10.1155/2010/472760.

[20] R. A. Poliquin, R. T. Rockafellar And L. Thibault, Local differentiability of distance functions, Transactions of the American Mathematical Society, 352, (2000), 5231-5249.

[21] J. PARIDA AND A. SEN, A variational-like inequality for multifunctions with applications, Journal of Mathematical Analysis and Applications, 124, (1987), 73-78.

[22] L. P. PANG, J. SHEN AND H. S. Song, A modified predictor-corrector algorithm for solving nonconvex generalized variational inequalities, Computers \& Mathematics with Applications, 54, (2007), 319-325.

[23] S. SuAntai And N. Petrot, Existence and stability of iterative algorithms for the system of nonlinear quasi-mixed equilibrium problems, Applied Mathematics Letters, 24, (2011), 308-313.

[24] G. Stampacchia, Formes bilineaires coercitives sur les ensembles convexes, Comptes Rendus de l'Académie des Sciences Paris, 258, (1964), 4413-4416.

[25] R. U. Verma, Projection methods, algorithms and a new system of nonlinear variational inequalities, An International Journal computers \& mathematics with Applications, 41, (2001), 1025-1031.

[26] R. U. Verma, General convergence analysis for two-step projection methods and applications to variational problems, Applied Mathematics Letters, 18, (2005), 1286-1292. 